\title{
Article \\ Selection of Atoxigenic Aspergillus flavus for Potential Use in Aflatoxin Prevention in Shandong Province, China
}

\author{
Jia Xu ${ }^{1}$, Peng Wang ${ }^{1}$, Zehua Zhou ${ }^{2}$, Peter John Cotty ${ }^{1}$ (D) and Qing Kong ${ }^{1, *(D)}$ \\ 1 School of Food Science and Engineering, Ocean University of China, Qingdao 266003, China; \\ Xuj970719@163.com (J.X.); wangp960517@163.com (P.W.); cottypj@gmail.com (P.J.C.) \\ 2 Food Technology Department, Wageningen University \& Research, 6700 AK Wageningen, The Netherlands; \\ zehua.zhou@wur.nl \\ * Correspondence: kongqing@ouc.edu.cn; Tel.: +86-532-8203-2290; Fax: +86-532-8203-238
}

check for

updates

Citation: Xu, J.; Wang, P.; Zhou, Z.; Cotty, P.J.; Kong, Q. Selection of Atoxigenic Aspergillus flavus for Potential Use in Aflatoxin Prevention in Shandong Province, China. J. Fungi 2021, 7, 773. https://doi.org/ 10.3390/jof7090773

Academic Editors: Pooja

Bhatnagar-Mathur and Julio

Alberto Zygadlo

Received: 4 June 2021

Accepted: 13 September 2021

Published: 18 September 2021

Publisher's Note: MDPI stays neutral with regard to jurisdictional claims in published maps and institutional affiliations.

Copyright: (c) 2021 by the authors. Licensee MDPI, Basel, Switzerland. This article is an open access article distributed under the terms and conditions of the Creative Commons Attribution (CC BY) license (https:/ / creativecommons.org/licenses/by/ $4.0 /)$.

\begin{abstract}
Aspergillus flavus is a common filamentous fungus widely present in the soil, air, and in crops. This facultative pathogen of both animals and plants produces aflatoxins, a group of mycotoxins with strong teratogenic and carcinogenic properties. Peanuts are highly susceptible to aflatoxin contamination and consumption of contaminated peanuts poses serious threats to the health of humans and domestic animals. Currently, the competitive displacement of aflatoxin-producers from agricultural environments by atoxigenic $A$. flavus is the most effective method of preventing crop aflatoxin contamination. In the current study, 47 isolates of $A$. flavus collected from peanut samples originating in Shandong Province were characterized with molecular methods and for aflatoxin-producing ability in laboratory studies. Isolates PA04 and PA10 were found to be atoxigenic members of the L strains morphotype. When co-inoculated with A. flavus NRRL3357 at ratios of 1:10, 1:1, and 10:1 (PA04/PA10: NRRL3357), both atoxigenic strains were able to reduce aflatoxin $\mathrm{B}_{1}\left(\mathrm{AFB}_{1}\right)$ levels, on both culture media and peanut kernels, by up to $90 \%$. The extent to which atoxigenic strains reduced contamination was correlated with the inoculation ratio. Abilities to compete of PA04 and PA10 were also independently verified against local aflatoxin-producer PA37. The results suggest that the two identified atoxigenic strains are good candidates for active ingredients of biocontrol products for the prevention of aflatoxin contamination of peanuts in Shandong Province.
\end{abstract}

Keywords: atoxigenic strains; Aspergillus flavus; aflatoxin contamination; competitive inhibition

\section{Introduction}

Aflatoxins are a group of toxic, carcinogenic, secondary metabolites produced primarily by members of the Aspergillus section Flavi [1]. Exposure to even small concentrations of aflatoxins may lead to immunosuppression, cancer, and stunted growth, while ingestion of high concentrations may result in acute symptoms including hepatitis, liver necrosis, and death [2]. From 2004 to 2006, a severe outbreak of acute aflatoxin poisoning occurred in Kenya, resulting in 317 cases with a 39\% fatality rate [3]. The major classes of aflatoxins are aflatoxin $B_{1}\left(A F B_{1}\right)$, aflatoxin $B_{2}\left(A F B_{2}\right)$, aflatoxin $G_{1}\left(A F G_{1}\right)$, and aflatoxin $G_{2}\left(A F G_{2}\right)$, of which $\mathrm{AFB}_{1}$ is the most common and toxic. Typically, most strains of $A$. flavus produce only $B$ aflatoxins [4]. Contamination usually begins during crop development when the crop is associated with aflatoxin-producing fungi. Contamination may continue and become much more severe after the harvest if crop and storage conditions are not optimal. Aflatoxins may cause serious food and feed safety problems worldwide, resulting in serious economic losses [5]. As one of the host crops most susceptible to aflatoxin contamination, peanuts have been plagued by perennial contamination problems [6]. The ability of different strains of $A$. flavus to produce aflatoxin varies greatly, and in the natural environment, genotypes that produce aflatoxins are present at the same time as genotypes without the capacity to produce aflatoxins [7-9]. Generally, A. flavus populations are divided into two morphotypes based on sclerotia size: $S$ strains (sclerotia diameter $<400 \mu \mathrm{m}$ ), L strains (sclerotia 
diameter $>400 \mu \mathrm{m}$ ) and physiology. The $\mathrm{S}$ and $\mathrm{L}$ strain morphotypes produce significant differences in the number of sclerotia and spores, and on average, $\mathrm{S}$ strain genotypes produce higher levels of aflatoxins [10-13]. In addition, genotypes also vary in ability to produce cyclopiazonic acid (CPA) a less toxic secondary metabolite [14]. Currently, researchers were divided on whether active ingredients capable of producing CPA should be considered for biocontrol products $[15,16]$.

In addition to effects on the health of humans and domestic animals, aflatoxins are a detriment to agricultural economies. Aflatoxins in crops can lead to loss of markets and even crop destruction. Expenses for monitoring and decontamination can also be significant [17]. Therefore, it is desired that farmers effectively prevent the formation of aflatoxins in crops. The use of fungicides, timely irrigation, and alternate planting systems have shown limited effects in preventing aflatoxin contamination [18], and the safety and cost/benefit balance of these procedures are still unclear [18,19]. At present, the use of native atoxigenic strains endemic to target areas is the most effective tool for preventing contamination. Through these techniques, aflatoxin-producers are displaced by atoxigenic strains during competition throughout treated fields, resulting in lower frequencies of aflatoxin-producers and corresponding reductions of aflatoxins in crops [20]. The biological control products containing atoxigenic strain as an active ingredient can reduce the aflatoxin content of cash crops by 70-99\% [21].

From Arizona cottonseed, AF36, the first and longest registered atoxigenic A. flavus (the active ingredient) is used on corn, cottonseed, almonds, figs, and pistachios [22]. AF36 is unable to produce the prerequisite substances necessary for aflatoxin formation due to a defect in the aflatoxin biosynthesis gene $p k s A$, but it has an intact CPA biosynthesis gene cluster [23,24]. In Georgia peanuts, A. flavus NRRL21882, the active ingredient of the biocontrol agent Afla-Guard ${ }^{\circledR}$, was isolated with deletion of the entire aflatoxin and CPA biosynthetic gene cluster. Afla-Guard ${ }^{\circledR}$ is used to manage aflatoxin contamination in peanuts and corn $[25,26]$. Although, biocontrol strains have been increasingly adopted worldwide, work on biocontrol needs to be expanded to determine the most cost-effective manner to implement this technology to improve human well-being, the viability of agriculture, and environmental health. As more biocontrol programs are adopted globally to reduce aflatoxin contamination, strains used as biopesticides should be sourced from local fungal populations to reduce the risk of unpredictable ecological outcomes of nonnative introduced organisms $[27,28]$.

At present, China is the world's largest peanut producer [29], and Shandong is one of the four major peanut-producing provinces in China. In Shandong, aflatoxin contamination is a central concern. However, biocontrol products with atoxigenic $A$. flavus active ingredients are not available in Shandong. The current study sought to identify atoxigenic A. flavus associated with peanut production in Shandong and to assess the potential of the fungi as active ingredients of biocontrol products directed at limiting aflatoxin contamination. During the process, two atoxigenic genotypes of A. flavus with the capacity to reduce aflatoxin contamination of peanut were cultured from Shandong peanuts. These two A. flavus genotypes have potential as active ingredients in biocontrol products directed at preventing aflatoxin contamination in the vital peanut production region of China's North Central Plain.

\section{Materials and Methods}

\subsection{Fungal Isolates and Culture Conditions}

Two peanut samples from Shandong Province were crushed, suspended in sterile water $(10 \mathrm{~g}$ in $90 \mathrm{~mL})$, and subjected to dilution plate technique on CU medium as modified by Kachapulula et al. [2]. After incubation of plates at $30^{\circ} \mathrm{C}$ for $3-5 \mathrm{~d}$ members of Aspergillus section Flavi were transferred to $5 / 2$ medium ( $5 \%$ V8 vegetable juice, $2 \%$ agar, $\mathrm{pH} 5.2$ ) and incubated for 5 days at $30^{\circ} \mathrm{C}$ under dark conditions. Cultures were then stored as plugs of sporulating cultures in glass vials containing sterile distilled water. 
Two aflatoxin-producers were used in competition experiments designed to identify A. flavus with potential value as biocontrol agents directed at preventing aflatoxin contamination. NRRL3357 was the standard aflatoxin producer. Isolate PA37 was selected as a local aflatoxin producer from Shandong peanuts to ensure competitiveness against local causal agents of contamination.

\subsection{Characterization of Atoxigenic A. flavus}

\subsubsection{Morphological Identification}

Sporulating colonies were picked from $5 / 2$ medium and were stored in brown strain preservation bottles containing $1 / 3$ volume of sterile water at room temperature. Mature mycelia were selected and placed on slides, sections were made by adding $0.85 \%$ saline dropwise, and observed under a light microscope $(10 \times$ eyepiece, $40 \times$ objective $)$. Isolates were incubated on Wickerham medium as modified by Chang et al. [26] at $30{ }^{\circ} \mathrm{C}$ for 14 days after which conidia were washed from colonies with $95 \%$ ethanol, discarded, and formation of sclerotia on the agar surface was observed [30].

\subsubsection{Molecular Identification}

Genomic DNA was extracted with omega DNA Fungal DNA Kit (D3390, Omega BioTek, Georgia, USA) and molecular identification of the strains to be tested was performed using fungal universal primers (ITS1: TCCGTAGGTGAACCTGCGG, ITS4: TCCTCCGCTTATTGATATGC). The PCR products were sent to Qingdao Rui-Biotech Co., Ltd. (Qingdao, China) for sequencing, and the sequencing results were blasted in NCBI.

\subsubsection{Cluster Amplification Patterns}

Cluster amplification pattern (CAP) is a rapid multiplex PCR method used to identify and monitor indels in the aflatoxin biosynthesis gene cluster and adjacent regions [31]. The CAP method was slightly modified from Callicott et al. [31]. Genomic A. flavus DNA was used as templates for PCR reactions using the primers and panel mixes from Callicott et al. [31]. DNA of A. flavus NRRL3357 served as the standard in all reactions. Reaction system: $0.8 \mu \mathrm{L}$ Panel Mix, $3 \mu \mathrm{L}$ DNA template, $10 \mu \mathrm{L} 2 \times$ PCR Mix, sterile water to $20 \mu \mathrm{L}$ total. Reaction conditions: pre-denaturation $94{ }^{\circ} \mathrm{C}, 1 \mathrm{~min}$, then 30 cycles of denaturation $94^{\circ} \mathrm{C}, 30 \mathrm{~s}$, annealing $62^{\circ} \mathrm{C}, 90 \mathrm{~s}$, extension $72^{\circ} \mathrm{C}, 90 \mathrm{~s}$ for 30 cycles, followed by a final extension of $72{ }^{\circ} \mathrm{C}$ for $10 \mathrm{~min}$. PCR products were stored at $4{ }^{\circ} \mathrm{C}$ until results were visualized following $1 \%$ agarose electrophoresis.

\subsubsection{Aflatoxin Content in YES Media}

Aflatoxin was extracted with methanol from seven-day cultures $\left(30^{\circ} \mathrm{C}\right.$ stationary incubation) in YES media. The cultures containing methanol were shaken on an orbital shaker for $1 \mathrm{~h}$ at $200 \mathrm{rpm}$ and 30 degrees. The methanol culture mixtures were placed in a centrifuge at $3500 \times g$ for $15 \mathrm{~min}$. Supernatants were applied to aflatoxin purification columns and $50 \mu \mathrm{L}$ of the effluent was subjected to high-performance liquid chromatography with a Hewlett-Packard Model 1100 pump (Palo Alto, CA, USA) connected to a Hewlett-Packard Model 1046A programmable fluorescence detector and a Hewlett-Packard Kayak XA (Hewlett-Packard Chemistry Station version 06.01) data module. Chromatographic separation was performed on a C18 reversed-phase column $(150 \mathrm{~mm} \times 4.6 \mathrm{~mm}$ ID, $5 \mu \mathrm{m}$ particle size; Luna-Phenomenex, Torrance, CA, USA) connected to a pre-column safety guard $(20 \mathrm{~mm} \times 4.6 \mathrm{~mm}$ ID, $5 \mu \mathrm{m}$ particle size, Phenomenex). The mobile phase was water: methanol: acetonitrile $(4: 1: 1, v / v)$ with a flow rate of $1.5 \mathrm{~mL} / \mathrm{min}$ and detection limits of $0.1 \mathrm{ng} / \mathrm{g} \mathrm{AFB}_{1}$ and $\mathrm{AFG}_{1}$ and $0.03 \mathrm{ng} / \mathrm{g} \mathrm{AFB}_{2}$ and $\mathrm{AFG}_{2}$. Comparisons were made to known aflatoxin standards (Sigma Aldrich, St. Louis, MO, USA).

\subsubsection{CPA Content Determination}

Isolates PA04 and PA10 were incubated on Wickerham medium as modified by Chang et al. [26] for 7 days at $30{ }^{\circ} \mathrm{C}$, and CPA was extracted with trichloromethane at 
$30^{\circ} \mathrm{C}$ on an orbital shaker $200 \mathrm{rpm}$, for $30 \mathrm{~min}$. The extract was passed through a Whatman 1 filter paper and concentrated by evaporation at room temperature. CPA concentrations were determined after thin-layer chromatography (TLC) on silica Gel G plates (105554) following the method of Chang et al. [26].

\subsection{Competitive Analysis}

Isolates PA04, PA10, PA37, and A. flavus NRRL3357 were incubated on YES medium at $30^{\circ} \mathrm{C}$ for seven days, and the spores were washed off the plates with $0.01 \%$ Tween- 80 to make a spore suspension. Suspensions were mixed with a vortex and spores were counted with a hemocytometer under a light microscope. Spore suspensions were diluted to $10^{7}$ spores $/ \mathrm{mL}$. The concentration of spore suspensions was diluted so that the final concentrations of PA04 and PA10 were $10^{4}$ spores $/ \mathrm{mL}, 10^{5}$ spores $/ \mathrm{mL}$, and $10^{6}$ spores $/ \mathrm{mL}$. A. flavus NRRL3357 and PA37 spore suspension were diluted to a final concentration of $10^{5}$ spores/mL. Three mix ratios of 1:10, 1:1, and 10:1 (PA04:NRRL3357/PA37; PA10:NRRL3357/PA37) of A. flavus spore suspension were prepared.

\subsubsection{Competition of A. flavus on Peanuts}

Peanut kernels were surface-sterilized by soaking in $75 \%$ ethanol for $3 \mathrm{~min}$ and rinsing with sterile water. $10 \mathrm{~g}$ of surface-sterilized peanuts per $250 \mathrm{~mL}$ conical vial were inoculated with $1 \mathrm{~mL}$ of each of the mixed conidial suspensions described above. Flasks were gently shaken to evenly coat the peanut kernels with a final water content of $90 \%$. Peanuts inoculated with $A$. flavus NRRL3357/PA37 were the control treatments. Treatments were replicated three times. The conical vials were sealed with a breathable film to prevent contamination and incubated stationary at $30{ }^{\circ} \mathrm{C}$ and $85 \%$ humidity. $\mathrm{AFB}_{1}$ was quantified after 7 days.

\subsection{2. $\mathrm{AFB}_{1}$ Content of Inoculated Peanut}

After seven days, A. flavus inoculated kernels were ground and one gram of ground peanut was added to $10 \mathrm{~mL}$ of methanol and shaken on an orbital shaker at $30^{\circ} \mathrm{C}, 200 \mathrm{rpm}$, for 1 hour. Extracts were centrifuged at $3500 \times g$ for $15 \mathrm{~min}$. The grinder was cleaned with ethanol to remove residues between samples. The supernatant was concentrated to $0.1 \mathrm{~mL}$ and subjected to a semi-quantitative aflatoxin analysis using TLC. TLC plates (Merck, Darmstadt, Germany) were developed in methanol: ethyl acetate: acetic acid (96:3:1) and air-dried. Aflatoxin was visible under $365 \mathrm{~nm}$ UV light. Extracts verified to have $\mathrm{AFB}_{1}$ by TLC were analyzed using an ELISA kit for aflatoxin $B_{1}$ (Jiangsu Huisi Technology Co., Ltd., Jiangsu, China). The excitation and detection wavelengths were set at $360 \mathrm{~nm}$ and $450 \mathrm{~nm}$, respectively. Inhibition of aflatoxin biosynthesis was expressed as an inhibition ratio (A) and was calculated using Equation (1).

$$
\mathrm{A}=\left[1-\mathrm{C}_{2} / \mathrm{C}_{1}\right] \times 100 \%
$$

where:

$C_{1}$ is the concentration of aflatoxin $B_{1}$ in the sample, and $C_{2}$ is the concentration of aflatoxin $\mathrm{B}_{1}$ in control.

\subsubsection{Competition of A. flavus on Culture Media}

The mixed conidial suspension $(30 \mu \mathrm{L})$ spread evenly across PDA plates were compared with plates spread with NRRL3357 alone as a control. Each treatment was performed with three replicates, and cultures were grown in the dark at $30^{\circ} \mathrm{C}$ for 10 days. Methanol was used to wash all cultures on the surface of the medium. The cultures containing methanol were shaken on an orbital shaker for $1 \mathrm{~h}$ at $200 \mathrm{rpm}$ and 30 degrees. The methanol culture mixtures were placed in a centrifuge at $3500 \times g$ for 15 min after which AFB1 content was determined by TLC and ELISA kit. 


\subsubsection{Statistical Analysis}

The data were processed by SPSS 25 software. Treatments in all tests were replicated 3 times and means were subjected to Analysis of Variance and when significant differences were found, means were separated with Tukey's HSD test.

\section{Results}

\subsection{Characterization of A. flavus}

As shown in Figure 1, the colonies were initially flat, fluffy, and light yellow-green in color, and the center of the colonies was slightly elevated and slowly turned dark green in late maturity. Fungi with round or ellipsoidal vesicles with smooth spherical conidia were observed under $400 \times$. Sequencing of PCR products obtained with the ITS universal fungal primers indicated that both PA04 and PA10 are more than $99 \%$ identical to A. flavus. The sclerotia of $A$. flavus PA04 and PA10 had average sclerotial diameters of $>400 \mu \mathrm{m}$ indicating both genotypes belong to the L strain morphotype.

A

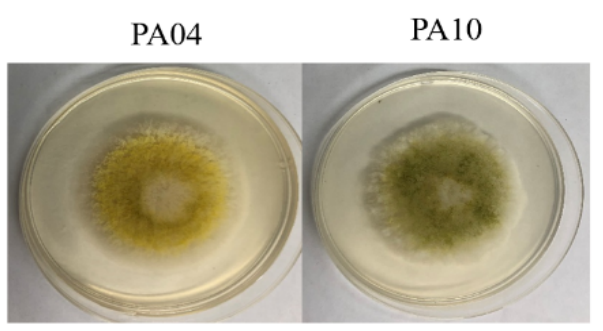

B

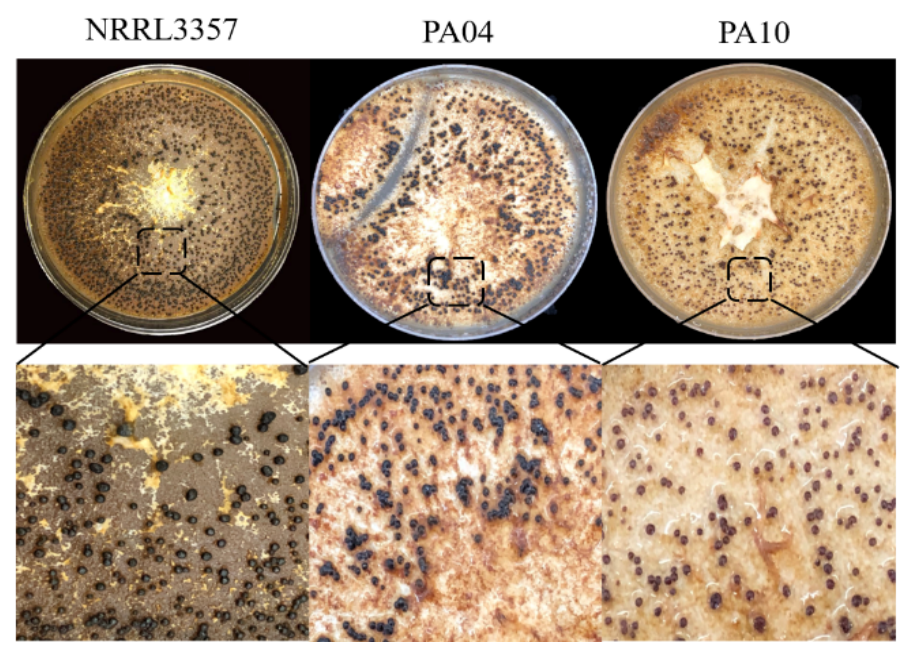

Figure 1. Aspergillus flavus PA04 and PA10 colonies incubated on Wickerham medium at $30{ }^{\circ} \mathrm{C}$ for $5 \mathrm{~d}(\mathrm{~A})$ and sclerotia from cultures incubated at $30^{\circ} \mathrm{C}$ for $14 \mathrm{~d}(\mathbf{B})$.

CAP analysis of two strains of A. flavus, PA04, and PA10, revealed different numbers of bands missing in Panel2, with PA04 missing fragment regions of AC06 and IC02, and PA10 missing fragment regions of AC06, AC07, and IC02 (Figure S1). These band patterns indicate missing aflatoxin biosynthesis genes. In addition, both strains PA04 and PA10 had a large number of missing bands in the CAP assay Panel 3 and Panel 4. Panel 3 and Panel 4 amplify portions of the CPA biosynthetic gene cluster. The results of CAP analysis indicated that the two strains, PA04 and PA10, lack the genes necessary to produce aflatoxins.

Furthermore, PA04 and PA10 were found to not produce aflatoxins at the minimum detection limit $(<0.1 \mathrm{ng} / \mathrm{mL}$ ) for the HPLC protocol (Figure 2) confirming that the lack of detectable aflatoxin biosynthesis genes resulted in PA04 and PA10 lacking the ability to produce aflatoxins. The amount of CPA produced by A. flavus was determined by TLC and it was found that PA04 and PA10 produced small quantities of CPA compared to A. flavus NRRL3357(Figure S2). 
A AF standard sample

$\Delta V$

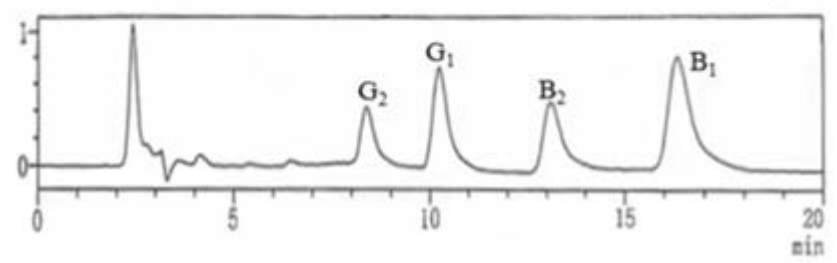

B

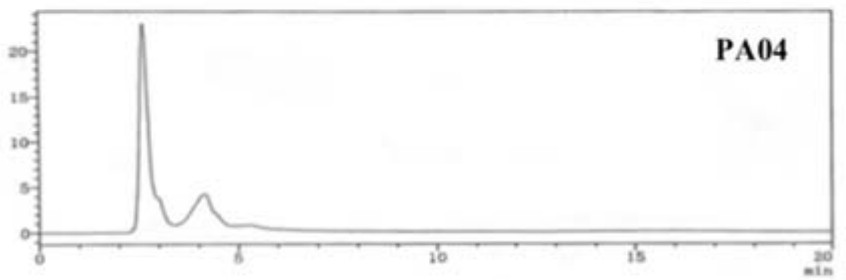

$\mathrm{C}=\mathrm{v}$

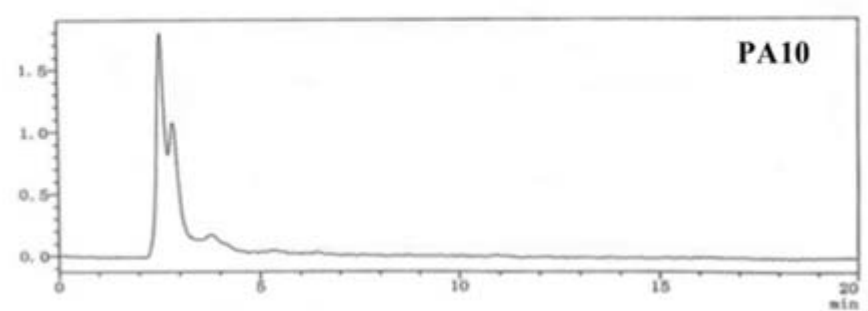

Figure 2. High performance liquid chromatography (HPLC) chromatogram indicating aflatoxin standard sample (A) and lack of aflatoxin production on YES medium $\left(30^{\circ} \mathrm{C}, 7 \mathrm{~d}\right)$ by both A. flavus PA04 (B) and PA10 (C).

\subsection{Inhibition of Aflatoxin Biosynthesis by Atoxigenic Genotypes PA04 and PA10}

After seven days of incubation, peanuts inoculated with all three spore mixtures had significantly fewer aflatoxins than peanuts inoculated with $A$. flavus NRRL3357 alone. The lowest aflatoxin concentrations were in peanuts inoculated with PA04 and NRRL3357 at a 10 to 1 ratio (Figure 3). As the percent of atoxigenic strain in the inoculum increased, the aflatoxin content decreased (Figure 4). In addition, the $\mathrm{AFB}_{1}$ content of different inoculation ratios was measured using the Elisa method (Table S1). When the inoculation ratio was 10:1 (PA04:NRRL3357), the lowest $\mathrm{AFB}_{1}$ content was $923.1 \mathrm{ng} / \mathrm{mL}$ (Figure 4), and the $\mathrm{AFB}_{1}$ inhibition rate was $95.72 \%$ (Figure 5). When the inoculation ratio was 1:10 (PA04:NRRL3357), $\mathrm{AFB}_{1}$ inhibition was $20.18 \%$, and its $\mathrm{AFB}_{1}$ content was $17,209.6 \mathrm{ng} / \mathrm{mL}$. When co-inoculated with PA37, more obvious competitiveness was obtained. When the inoculation ratio was 10:1 (PA04:PA37), the lowest $\mathrm{AFB}_{1}$ content was $171.7 \mathrm{ng} / \mathrm{mL}$ (Figure 4), and the $\mathrm{AFB}_{1}$ inhibition rate was $91.31 \%$ (Figure 5). When the inoculation ratio was 1:10 (PA04:PA37), $\mathrm{AFB}_{1}$ inhibition was $39.10 \%$ (Figure 5), and its $\mathrm{AFB}_{1}$ content was $1024.1 \mathrm{ng} / \mathrm{mL}$ (Figure 4). Inoculum containing PA10 had similar results on peanuts. When the inoculation ratio was 10:1 (PA10:NRRL3357), the lowest detected $\mathrm{AFB}_{1}$ content occurred $1067.1 \mathrm{ng} / \mathrm{mL}$ (Figure 4) and the $\mathrm{AFB}_{1}$ inhibition rate was $95.05 \%$ (Figure 5). When the inoculation ratio was 1:10 (PA10:NRRL3357), $\mathrm{AFB}_{1}$ inhibition was $16.47 \%$ (Figure 5) and the $\mathrm{AFB}_{1}$ concentrations averaged $18,561.1 \mathrm{ng} / \mathrm{mL}$ (Figure 4 ). When the inoculation ratio was 10:1 (PA10:PA37), the lowest detected $\mathrm{AFB}_{1}$ content occurred $148.0 \mathrm{ng} / \mathrm{mL}$ (Figure 4) and the $\mathrm{AFB}_{1}$ inhibition rate was $92.51 \%$ (Figure 5 ). When the inoculation ratio was $1: 10$ (PA10:PA37), $\mathrm{AFB}_{1}$ inhibition was $28.16 \%$ (Figure 5) and the $\mathrm{AFB}_{1}$ concentrations averaged $1204.1 \mathrm{ng} / \mathrm{mL}$ (Figure 4). 



Figure 3. Thin layer chromatographs visualized under $365 \lambda$ UV light for aflatoxin extracts from co-inoculation experiments. Aflatoxin producer NRRL3357 alone and co-inoculated with three concentrations of either PA10 or PA04 and incubated at $30{ }^{\circ} \mathrm{C}$ for seven days on peanut $(\mathbf{A}, \mathbf{B})$ and $10 \mathrm{~d}$ on PDA medium $(\mathbf{E}, \mathbf{F})$. Aflatoxin producer PA37 alone and co-inoculated with three concentrations of either PA10 or PA04 and incubated at $30^{\circ} \mathrm{C}$ for seven days on peanut (C,D).

A

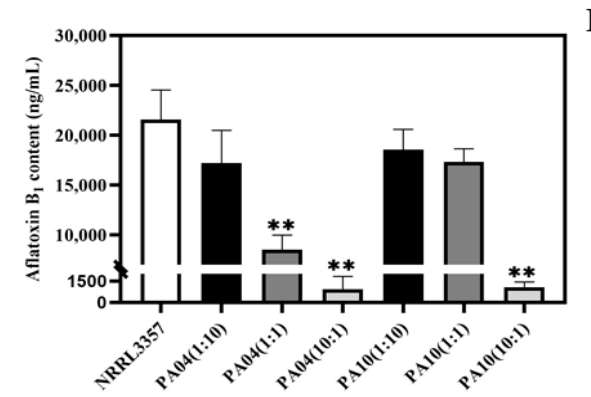

C

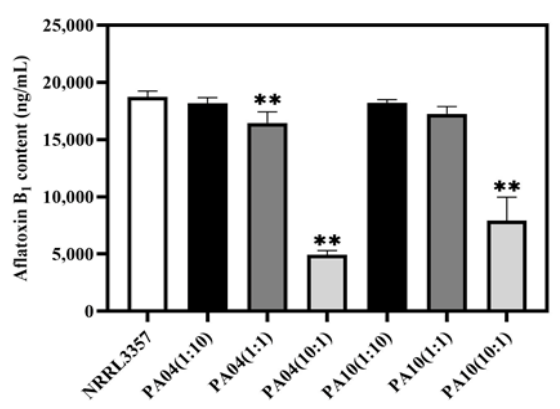

B

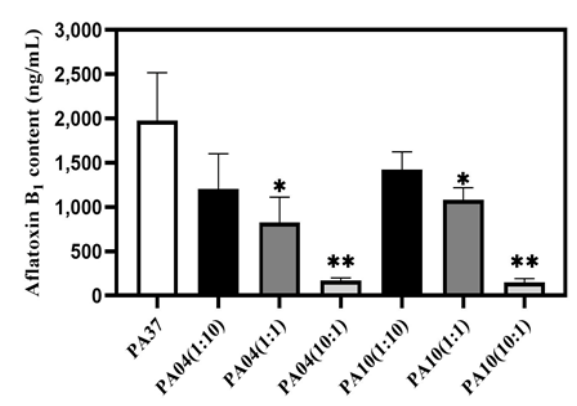

Figure 4. $\mathrm{AFB}_{1}$ concentrations as determined by ELISA resulting from co-culture of ei ther atoxigenic strains with NRRL3357/PA37. Peanut inoculated with different proportions of $A$. flavus strains and incubated at $30^{\circ} \mathrm{C}$ for seven days $(\mathbf{A}, \mathbf{B})$. PDA media inoculated with different proportions of $A$. flavus strains and incubated at $30{ }^{\circ} \mathrm{C}$ for 10 days (C). $\left({ }^{*} p<0.05,{ }^{* *} p<0.001\right)$. 
A

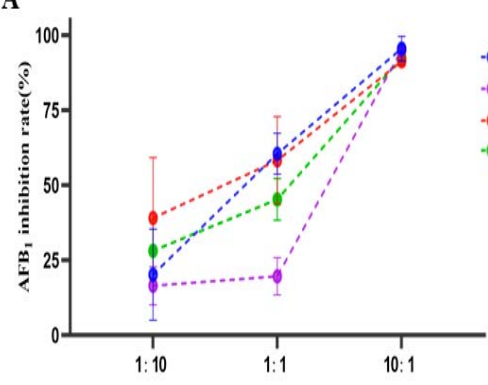

B

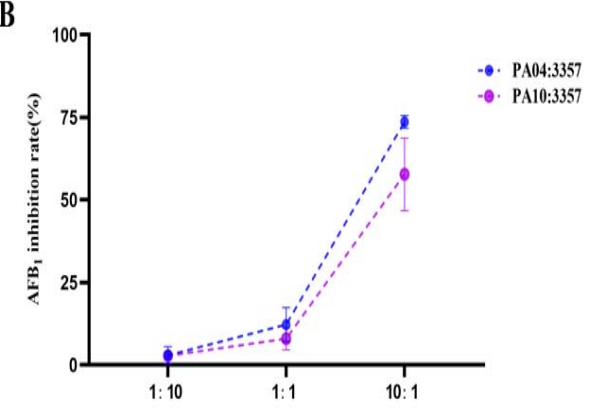

Figure 5. Inhibition of $\mathrm{AFB}_{1}$ biosynthesis by NRRL 3357 or PA37 with co-inoculation of different proportions of atoxigenic strains on peanuts at $30^{\circ} \mathrm{C}$ for seven days (A). Inhibition of $\mathrm{AFB}_{1}$ production by NRRL 3357 with different inoculation ratios cultured on PDA at $30^{\circ} \mathrm{C}, 10 \mathrm{~d}(\mathbf{B})$.

After 14 days incubation, inoculations with genotype mixtures exhibited similar inhibition as that found 7 days after inoculation, with the aflatoxin content decreasing as the proportion of atoxigenic $A$. flavus increased. Using ELISA, treatments with an inoculation ratio was 10:1 (PA04:NRRL3357) had the lowest $\mathrm{AFB}_{1}$ content $(1296.5 \mathrm{ng} / \mathrm{mL}$; Figure S3), and the $\mathrm{AFB}_{1}$ inhibition rate was as high as $83.39 \%$ (Figure $\mathrm{S} 4$ ). When the inoculation ratio was 1:10 (PA04:NRRL3357), the lowest $\mathrm{AFB}_{1}$ inhibition rate occurred $28.46 \%$ (Figure S4), with $\mathrm{AFB}_{1}$ concentrations averaging $6649.8 \mathrm{ng} / \mathrm{mL}$ (Figure S3). Similarly, with PA10, a ratio of 10:1 (PA10:NRRL3357) resulted in the lowest $\mathrm{AFB}_{1}$ concentrations detected $\left(1142.1 \mathrm{ng} / \mathrm{mL}\right.$ ) and $\mathrm{AFB}_{1}$ inhibition averaged $87.72 \%$. However, when the inoculation ratio was 1:10 (PA04:NRRL3357), aflatoxin biosynthesis was only slightly inhibited, and the $\mathrm{AFB}_{1}$ inhibition rate was only $8.76 \%$ with an $\mathrm{AFB}_{1}$ content of $8473.6 \mathrm{ng} / \mathrm{mL}$. Aflatoxin concentrations measured with TLC provided similar results (Figure S5).

Competition on PDA yielded similar results to competition on peanuts, only with less variability. As the proportion of the spore mixture composed of either PA04 or PA10 increased, inhibition of aflatoxin biosynthesis increased (Figure 3). However, percent inhibition on agar was less than that observed on peanuts (Figure 5). The lowest mean $\mathrm{AFB}_{1}$ concentration was $4947.0 \mathrm{ng} / \mathrm{mL}$ and the highest was $18,187.4 \mathrm{ng} / \mathrm{mL}$ when NRRL3357 was mixed with PA04. The lowest $\mathrm{AFB}_{1}$ inhibition rate was $2.96 \%$ and the highest $\mathrm{AFB}_{1}$ inhibition rate was $73.60 \%$. When PA10 was mixed with NRRL3357, the lowest level of $\mathrm{AFB}_{1}$ was $7922.3 \mathrm{ng} / \mathrm{mL}$ and the highest level was $18,212.3 \mathrm{ng} / \mathrm{mL}$, with the lowest rate of $\mathrm{AFB}_{1}$ inhibition being $2.82 \%$ and the highest inhibition $57.73 \%$. Overall, inhibition of aflatoxin biosynthesis by the two atoxigenic strains PA04 and PA10 on PDA was less than on peanuts.

\section{Discussion}

Shandong Province, one of the largest peanut-producing areas in China, has a long history of peanut aflatoxin contamination. This contamination severely limits economic development. Dorner et al. [32] found that spraying field plots with a mixture of atoxigenic $A$. flavus and atoxigenic $A$. parasiticus reduced pre-harvest aflatoxin contamination of peanuts, and also had a beneficial legacy effect of reducing aflatoxin contamination during storage. Since that time several atoxigenic strain-based granular products have been developed for use on peanuts and are in use on commercial peanuts in the US, Senegal, Nigeria, and the Gambia [33-35]. The use of native atoxigenic A. flavus as a biocontrol agent to prevent aflatoxin contamination has several advantages including low environmental impact. Atoxigenic strains theoretically have similar adaptations and environmental competence as aflatoxin producers and atoxigenic strains are equally effective at colonizing and utilizing crop tissues [10]. It has repeatedly been suggested that native endemic atoxigenic genotypes are superior to introduced genotypes [36] due to better adaptation to the target agroecosystem and associated niches. In addition, the use of endemic fungi reduces the risk of any potential detrimental influences on the environment and non- 
target hosts and avoids potential unforeseen and undesirable outcomes from biological invasions [37,38].

In this study, two atoxigenic L strain morphotype A. flavus genotypes PA04 and PA10 were obtained from peanut kernels collected in Shandong Province. When co-inoculated with A. flavus NRRL3357 and local aflatoxin-producer PA37, these atoxigenic genotypes displayed superior competitiveness. Generally, lower concentrations of aflatoxins are produced by L strain A. flavus compared to S strain A. flavus [12,39]. Some L morphotype A. flavus lack ability to produce aflatoxin [11] and some of the molecular events that led to atoxigenicity occurred many thousands of years BPE [40]. In addition, L strain A. flavus produce large numbers of conidia which are advantageous in airborne transmission and crop establishment [41]. The frequency of $A$. flavus genotypes in communities of aflatoxinproducing fungi is determined in part by the number of conidia and this frequency has an impact on the level of crop aflatoxin contamination [42].

The two atoxigenic A. flavus genotypes, PA04 and PA10, identified in the current study, are native to Shandong Province, and both reduce aflatoxin levels in peanuts and on PDA media (Figure 4). The extent to which aflatoxin biosynthesis is inhibited is correlated with the proportion of atoxigenic strain conidia present. These results suggest that both of these atoxigenic $A$. flavus have the potential for biological control of aflatoxin contamination of peanuts in Shandong Province. The sclerotia of $A$. flavus is an important survival structure in soil and plant residues. Sclerotia generate conidia when germinating under favorable conditions. Thus, the production of sclerotia provides A. flavus increased potential to overwinter [43].

However, PA04 and PA10 produce both abundant sclerotia and spores. Both PA04 and PA10 are good candidates either individually or in combination for active ingredients of biocontrol products directed at managing aflatoxins in China. The two atoxigenic $A$. flavus were more effective at inhibiting aflatoxin biosynthesis on peanuts than on PDA. Superior competitiveness on peanuts may have increased the likelihood that these genotypes would be isolated from Shandong peanuts in the current study. In the field, applied biocontrol strains must be competitive against aflatoxin-producers during dispersal and crop colonization. Meanwhile, the formulation of biocontrol fungi must be able to effectively deliver the necessary number of conidia to gain a competitive advantage at an acceptable cost [27]. Therefore, field studies on the efficacy and persistence of these two atoxigenic strains of A. flavus under standard agronomic practices in the target areas are necessary [44]. Currently, the most practical method for delivering atoxigenic stains for aflatoxin management is to combine the atoxigenic fungi with a food source, usually a grain or a grain byproduct. After application, the fungus utilizes the nutrients in the formulation to support mycelial growth and spore formation [27]. To protect crops from aflatoxin contamination in the long term, the natural diversity of aflatoxin populations in agricultural soils needs to be further understood and optimal practices to utilize atoxigenic A. flavus as biocontrol agents should be explored [45].

It is important to limit potential risks associated with biocontrol including prevention of crop damage and damage to the soil microbiota. Atoxigenic strains have been used to greatly reduce aflatoxin-contamination in commercial agriculture since 1996 without observed detrimental effects [23,27]. Atoxigenic A. flavus strains PA04 and PA10, identified in the current study, are highly promising candidate fungi for active ingredients for biocontrol products directed at preventing aflatoxin contamination in Shandong Province, China. The potential of these fungi and the track record of atoxigenic strain-based biocontrol provide an opportunity to improve both the prosperity of Shandong agriculture and the health of the population that consumes Shandong-produced peanuts. Field trials directed at evaluating and optimizing the use of PA04 and PA10 in Shandong are needed.

Supplementary Materials: The following are available online at https:/ / www.mdpi.com/article / 10.3390/jof7090773/s1. Figure S1: The electrophoretogram of 14 strains of Aspergillus flavus were selected from different samples and different batches; Figure S2: The CPA content of A. flavus PA04 and PA10 was determined by thin layer chromatography (TLC); Figure S3: Determination of AFB 1 
content in peanut cultured for $14 \mathrm{~d}$ by ELISA; Figure S4: Inhibition of $\mathrm{AFB}_{1}$ biosynthesis by NRRL 3357 with co-inoculation of different proportions of atoxigenic strains on peanuts at $30^{\circ} \mathrm{C}$ for $14 \mathrm{~d}$; Figure S5: Determination of aflatoxin content in peanut cultured for $14 \mathrm{~d}$ by TLC; Table S1: Reduction of $\mathrm{AFB}_{1}$ content by co-inoculation with atoxigenic $A$. flavus.

Author Contributions: Conceptualization, Q.K., P.J.C. and J.X.; methodology, Q.K., J.X. and P.W.; formal analysis, Q.K., P.W. and J.X.; investigation, J.X., Z.Z. and P.W.; writing-original draft preparation, J.X.; writing-review and editing, Q.K., P.J.C. All authors contributed to writing and reviewing the paper. All authors have read and agreed to the published version of the manuscript.

Funding: National Natural Science Foundation of China (32072328), and the National Key R\&D Program of China (2019YFD0901705).

Institutional Review Board Statement: Not applicable.

Informed Consent Statement: Not applicable.

Conflicts of Interest: The authors declare no conflict of interest.

\section{References}

1. Mahuku, G.; Nzioki, H.S.; Mutegi, C.; Kanampiu, F.; Narrod, C.; Makumbi, D. Pre-harvest management is a critical practice for minimizing aflatoxin contamination of maize. Food Control 2018, 96, 219-226. [CrossRef]

2. Kachapulula, P.W.; Akello, J.; Bandyopadhyay, R.; Cotty, P.J. Aspergillus section Flavi community structure in Zambia influences aflatoxin contamination of maize and groundnut. Int. J. Food Microbiol. 2017, 261, 49-56. [CrossRef] [PubMed]

3. Azziz-Baumgartner, E.; Lindblade, K.; Gieseker, K.; Rogers, H.S.; Kieszak, S.; Njapau, H.; Schleicher, R.; McCoy, L.F.; Misore, A.; DeCock, K. Case-control study of an acute aflatoxicosis outbreak, Kenya. Environ. Health Perspect. 2005, 113, 1779-1783. [CrossRef]

4. Scherm, B.; Palomba, M.; Serra, D.; Marcello, A.; Migheli, Q. Detection of transcripts of the aflatoxin genes aflD, aflO, and aflP by reverse transcription-polymerase chain reaction allows differentiation of aflatoxin-producing and non-producing iso-lates of Aspergillus flavus and Aspergillus parasiticus. Int. J. Food Microbiol. 2005, 98, 201-210. [CrossRef]

5. Njoroge, S.M.C. A Critical Review of Aflatoxin Contamination of Peanuts in Malawi and Zambia: The Past, Present, and Future. Plant Dis. 2018, 102, 2394-2406. [CrossRef]

6. Torres, A.M.; Barros, G.G.; Palacios, S.A.; Chulze, S.N.; Battilani, P. Review on pre-and post-harvest man agement of peanuts to minimize aflatoxin contamination. Food Res. Int. 2014, 62, 11-19. [CrossRef]

7. Vaamonde, G.; Patriarca, A.; Pinto, V.F.; Comerio, R.; Degrossi, C. Variability of aflatoxin and cyclopiazonic acid production by Aspergillus section flavi from different substrates in Argentina. Int. J. Food Microbiol. 2003, 88, 79-84. [CrossRef]

8. Pildain, M.; Vaamonde, G.; Cabral, D. Analysis of population structure of Aspergillus flavus from peanut based on vegetative compatibility, geographic origin, mycotoxin and sclerotia production. Int. J. Food Microbiol. 2004, 93, 31-40. [CrossRef] [PubMed]

9. Razzaghi-Abyaneh, M.; Shams-Ghahfarokhi, M.; Allameh, A.; Kazeroon-Shiri, A.; Ranjbar-Bahadori, S.; Mirzahoseini, H.; Rezaee, M.-B. A Survey on Distribution of Aspergillus Section Flavi in Corn Field Soils in Iran: Population Patterns Based on Aflatoxins, Cyclopiazonic Acid and Sclerotia Production. Mycopathologia 2006, 161, 183-192. [CrossRef]

10. Cotty, P.J. Virulence and Cultural Characteristics of TwoAspergillus flavusStrains Pathogenic on Cotton. Phytopathology 1989, 79, 808-814. [CrossRef]

11. Geiser, D.M.; Dorner, J.W.; Horn, B.W.; Taylor, J.W. The Phylogenetics of Mycotoxin and Sclerotium Production in Aspergillus flavus and Aspergillus oryzae. Fungal Genet. Biol. 2000, 31, 169-179. [CrossRef]

12. Abbas, H.K.; Weaver, M.A.; Zablotowicz, R.M.; Horn, B.W.; Shier, W.T. Relationships between aflatoxin production and sclerotia formation among isolates of Aspergillus section Flavi from the Mississippi Delta. Eur. J. Plant Pathol. 2005, 112, $283-287$. [CrossRef]

13. Shane, S.M. Economic issues associated with aflatoxins. In The Toxicology of Aflatoxins: Human Health, Veterinary, and Agricultural Significance; Elsevier: Amsterdam, The Netherlands, 1993; pp. 513-527.

14. Brown, R.L.; Cotty, P.J.; Cleveland, T.E. Reduction in Aflatoxin Content of Maize by Atoxigenic Strains of Aspergillus flavus. J. Food Prot. 1991, 54, 623-626. [CrossRef]

15. Chalivendra, S.C.; DeRobertis, C.; Chang, P.-K.; Damann, K.E. Cyclopiazonic acid is a pathogenicity factor for As-pergillus flavus and a promising target for screening germplasm for ear rot resistance. Mol. Plant-Microbe Interact. 2017, 30, 361-373. [CrossRef] [PubMed]

16. Horn, B.W.; Dorner, J.J.A.; Microbiology, E. Regional differences in production of aflatoxin B1 and cyc lopiazonic acid by soil isolates of Aspergillus flavus along a transect within the United States. J. Clin. Microbiol. 1999, 65, 1444-1449.

17. Mitchell, N.J.; Bowers, E.; Hurburgh, C.; Wu, F. Potential economic losses to the US corn industry from aflatoxin contamination. Food Addit. Contam. Part A 2016, 33, 540-550. [CrossRef] [PubMed] 
18. Cleveland, T.E.; Dowd, P.F.; Desjardins, A.E.; Bhatnagar, D.; Cotty, P.J. United States Department of Agriculture-Agricultural Research Service research on pre-harvest prevention of mycotoxins and mycotoxigenic fungi in US crops. Pest Manag. Sci. 2003, 59, 629-642. [CrossRef]

19. Wei, D.; Zhou, L.; Selvaraj, J.N.; Zhang, C.; Xing, F.; Zhao, Y.; Wang, Y.; Liu, Y. Molecular characterization of atoxigenic Aspergillus flavus isolates collected in China. J. Microbiol. 2014, 52, 559-565. [CrossRef]

20. Agbetiameh, D.; Ortega-Beltran, A.; Awuah, R.T.; Atehnkeng, J.; Islam, M.-S.; Callicott, K.A.; Cotty, P.J.; Bandyopadhyay, R. Potential of Atoxigenic Aspergillus flavus Vegetative Compatibility Groups Associated With Maize and Groundnut in Ghana as Biocontrol Agents for Aflatoxin Management. Front. Microbiol. 2019, 10, 2069. [CrossRef]

21. Bhatnagar-Mathur, P.; Sunkara, S.; Bhatnagar-Panwar, M.; Waliyar, F.; Sharma, K.K. Biotechnological advances for combating Aspergillus flavus and aflatoxin contamination in crops. Plant Sci. 2015, 234, 119-132. [CrossRef]

22. Ortega-Beltran, A.; Grubisha, L.C.; Callicott, K.; Cotty, P.J. The vegetative compatibility group to which the US biocontrol agent Aspergillus flavus AF 36 belongs is also endemic to Mexico. J. Appl. Microbiol. 2016, 120, 986-998. [CrossRef]

23. Cotty, P.J. Biocompetitive exclusion of toxigenic fungi. In The Mycotoxin Factbook: Food and Feed Topics; Barug, D., Bhatnagar, D., van Egmond, H.P., van der Kamp, J.W., van Osenbruggen, W.A., Visconti, A., Eds.; Wageningen Academic Publisher: Wageningen, The Netherlands, 2006; pp. 179-197. ISBN 978-90-8686-006-7.

24. Doster, M.A.; Cotty, P.J.; Michailides, T.J. Evaluation of the atoxigenic Aspergillus flavus strain AF36 in pistachio orchards. Plant Dis. 2014, 98, 948-956. [CrossRef]

25. Chang, P.; Chang, T.D.; Katoh, K. Deciphering the origin of Aspergillus flavus NRRL21882, the active biocontrol agent of Afla-Guard®. Lett. Appl. Microbiol. 2020, 72, 509-516. [CrossRef] [PubMed]

26. Chang, P.-K.; Horn, B.W.; Dorner, J.W. Clustered genes involved in cyclopiazonic acid production are next to the af-latoxin biosynthesis gene cluster in Aspergillus flavus. Fungal Genet. Biol. 2009, 46, 176-182. [CrossRef] [PubMed]

27. Dorner, J.W. Biological Control of Aflatoxin Contamination of Crops. J. Toxicol. Toxin Rev. 2004, 23, 425-450. [CrossRef]

28. Garber, R.K.; Cotty, P.J. Formation of Sclerotia and Aflatoxins in Developing Cotton Bolls Infected by the S Strain of Aspergillus flavus and Potential for Biocontrol with an Atoxigenic Strain. Phytopathology 1997, 87, 940-945. [CrossRef]

29. Yang, B.; Zhang, C.; Zhang, X.; Wang, G.; Li, L.; Geng, H.; Liu, Y.; Nie, C. Survey of aflatoxin B1 and heavy metal con-tamination in peanut and peanut soil in China during 2017-2018. Food Control 2020, 118, 107372. [CrossRef]

30. Chang, P.-K.; Scharfenstein, L.L.; Mack, B.; Ehrlich, K.C. Deletion of the Aspergillus flavus orthologue of A. nidulans fluG reduces conidiation and promotes production of sclerotia but does not abolish aflatoxin biosynthesis. Appl. Environ. Microbiol. 2012, 78, 7557-7563. [CrossRef]

31. Callicott, K.; Cotty, P.J. Method for monitoring deletions in the aflatoxin biosynthesis gene cluster of Aspergillus flavus with multiplex PCR. Lett. Appl. Microbiol. 2014, 60, 60-65. [CrossRef] [PubMed]

32. Dorner, J.W.; Cole, R.J. Effect of application of nontoxigenic strains of Aspergillus flavus and A. parasiticus on subsequent aflatoxin contamination of peanuts in storage. J. Stored Prod. Res. 2002, 38, 329-339. [CrossRef]

33. Mehl, H.L.; Jaime, R.; Callicott, K.A.; Probst, C.; Garber, N.P.; Ortega-Beltran, A.; Grubisha, L.C.; Cotty, P.J. Aspergillus flavus diversity on crops and in the environment can be exploited to reduce aflatoxin exposure and improve health. Ann. N. Y. Acad. Sci. 2012, 1273, 7-17. [CrossRef]

34. Bandyopadhyay, R.; Ortega-Beltran, A.; Akande, A.; Mutegi, C.; Atehnkeng, J.; Kaptoge, L.; Senghor, A.; Adhikari, B.; Cotty, P. Biological control of aflatoxins in Africa: Current status and potential challenges in the face of climate change. World Mycotoxin J. 2016, 9, 771-789. [CrossRef]

35. Senghor, L.A.; Ortega-Beltran, A.; Atehnkeng, J.; Callicott, K.A.; Cotty, P.J.; Bandyopadhyay, R. The Atoxigenic Biocontrol Product Aflasafe SN01 Is a Valuable Tool to Mitigate Aflatoxin Contamination of Both Maize and Groundnut Cultivated in Senegal. Plant Dis. 2020, 104, 510-520. [CrossRef] [PubMed]

36. Probst, C.; Bandyopadhyay, R.; Price, L.E.; Cotty, P.J. Identification of Atoxigenic Aspergillus flavus Isolates to Reduce Aflatoxin Contamination of Maize in Kenya. Plant Dis. 2011, 95, 212-218. [CrossRef] [PubMed]

37. Petit, J.N.; Hoddle, M.S.; Grandgirard, J.; Roderick, G.K.; Davies, N. Successful spread of a biocontrol agent reveals a biosecurity failure: Elucidating long distance invasion pathways for Gonatocerus ashmeadi in French Polynesia. BioControl 2008, 54, 485-495. [CrossRef]

38. Savić, Z.; Dudaš, T.; Loc, M.; Grahovac, M.; Budakov, D.; Jajić, I.; Krstović, S.; Barošević, T.; Krska, R.; Sulyok, M. Biological control of aflatoxin in maize grown in Serbia. Toxins 2020, 12, 162. [CrossRef] [PubMed]

39. Chang, P.K. Genome-wide nucleotide variation distinguishes Aspergillus flavus from Aspergillus oryzae and helps to reveal origins of atoxigenic A. flavus biocontrol strains. J. Appl. Microbiol. 2019, 127, 1511-1520. [CrossRef] [PubMed]

40. Adhikari, B.N.; Bandyopadhyay, R.; Cotty, P.J. Degeneration of aflatoxin gene clusters in Aspergillus flavus from Africa and North America. AMB Express 2016, 6, 62. [CrossRef]

41. Cotty, P.J. Comparison of four media for the isolation ofAspergillus flavus group fungi. Mycopathologia 1994, 125, 157-162. [CrossRef] [PubMed]

42. Mehl, H.; Cotty, P.J. Variation in competitive ability among isolates of Aspergillus flavus from different vegetative compatibility groups during maize infection. Phytopathology 2010, 100, 150-159. [CrossRef]

43. Zhao, X.; Spraker, J.E.; Bok, J.W.; Velk, T.; He, Z.-M.; Keller, N.P. A Cellular Fusion Cascade Regulated by LaeA Is Required for Sclerotial Development in Aspergillus flavus. Front. Microbiol. 2017, 8, 1925. [CrossRef] 
44. Mauro, A.; Battilani, P.; Cotty, P.J. Atoxigenic Aspergillus flavus endemic to Italy for biocontrol of aflatoxins in maize. BioControl 2014, 60, 125-134. [CrossRef]

45. Ehrlich, K.C. Non-aflatoxigenic Aspergillus flavus to prevent aflatoxin contamination in crops: Advantages and limitations. Frointers Microbiol. 2014, 5, 50. [CrossRef] [PubMed] 